\title{
NATURAL PROCESSES AND TIME FLUCTUATIONS IN THE RADIOCARBON CONCENTRATION OF THE ATMOSPHERE
}

\author{
V A DERGACHEV and G E KOCHAROV
}

\author{
A F Ioffe Physico-Technical Institute Academy of Sciences \\ of the USSR, Leningrad, K-21, USSR
}

ABSTRACT. The concentration of radiocarbon in the earth's atmosphere is used to analyze the complex of problems associated with the study of various astrophysical, geophysical, and geochemical phenomena within the framework of the All-Union problem of Astrophysical Phenomena and Radiocarbon. Effects of the supernovae explosions, solar activity, geomagnetic field and climatic changes in the ${ }^{14} \mathrm{C}$ level in tree-rings are considered.

\section{INTRODUGTION}

A proper understanding of the nuclear interactions of cosmic rays in the earth's atmosphere and lithosphere, in interplanetary and interstellar matter, in lunar and planetary surface material resulting in the formation of a variety of secondary particles, radiations, and nuclides promotes progress in the study of natural processes on different time and spatial scales of the universe. For example, from the study of radionuclides, valuable information may be obtained on the origin, propagation, and variations of cosmic rays, on the processes in the solar interior and on its surface, and on the geomagnetic field changes and geochemical processes, etc.

Experimental and theoretical interest in cosmic-ray archaeology has apparently been stimulated by the development of radiocarbon dating (Libby, 1946). Systematic investigations of changes in cosmic-ray intensity by means of cosmogenic radiocarbon have been in progress in the USSR for about ten years. Konstantinov and Kocharov (1965) initiated an extensive survey of ${ }^{14} \mathrm{C}$ in tree-rings, and later, a study of ${ }^{10} \mathrm{Be}$ and ${ }^{26} \mathrm{Al}$ in deep-sediment. The most detailed information on the differential intensity of cosmic rays in the past can be obtained by measuring the concentration of radiocarbon in individual annual tree rings. The science of dendrochronology provides the possibility of operating in a fourth dimension, $i e$, with time, in some natural sciences.

Let us dwell briefly on certain aspects of the All-Union problem, astrophysical phenomena and radiocarbon.

\section{Supernovae explosions: $\gamma$ - and corpuscular components}

Supernovae are considered to be one of the major cosmic-ray sources. Hence, both high and low energy components of cosmic rays can be produced in supernovae explosions, which, in the vicinity of the solar system, would have an important effect on cosmic-ray characteristics. Konstantinov and Kocharov (1965) have pointed out the importance of studying the fast component, $\gamma$-radiation, from supernova explosions. Possible increases in ${ }^{14} \mathrm{C}$ production within the atmosphere from supernovae were discussed in their paper.

The ${ }^{14} \mathrm{C}$ production rate is defined by $\delta$-function due to the $\gamma$-component of supernova. The duration of the ${ }^{14} \mathrm{C}$ content variation is defined actually by processes of mixing radiocarbon in the natural reservoir, since 
the duration of supernovae flares is less than the mixing time of ${ }^{14} \mathrm{C}$ in the atmosphere and the transition time of ${ }^{14} \mathrm{C}$ to the ocean. At present, accurate data does not exist on supernovae masses, on which the intensity of emitted $\gamma$-rays depends strongly; neither do we know the distance to supernovae that burst in historical times, nor the part of total energy, converted into the $\gamma$-component. Table 1 shows the results of calculations of the amount of ${ }^{14} \mathrm{C}$ that can be generated in supernovae explosions in historical times (Dergachev and Kocharov, 1977). In calculations the total energy of supernovae was taken to be $10^{50} \mathrm{ergs}$. If it is found that the energy of cosmic rays from supernovae exceed this value, then the most perspective supernovae must be Vela, Tucho Brahe's, Cassiopeia nova, Crab Nebula.

The results of ${ }^{14} \mathrm{C}$ content measurements in tree-rings for the periods AD 1564 to 1583 and 1593 to 1615 covering the explosions of Kepler's and Tucho Brahe's supernovae (Kocharov and others, 1974) do not reveal a significant increase due to the $\gamma$-ray burst from these supernovae. However, these preliminary results yield the upper limit for the supernovae energy.

The discovery of pulsars that may be remnants of supernovae provides a possibility of determining the ages and distances of nearby supernovae.

The contribution of the corpuscular component from a nearby supernovae source can be dominated in the ${ }^{14} \mathrm{C}$ content variations (Dergachev, Kocharov, and Rumyantsev, 1970; Lingenfelter and Ramaty, 1970).

TABLE 1

Variation of ${ }^{14} \mathrm{C}$ content in the atmosphere

\begin{tabular}{|c|c|c|c|}
\hline $\begin{array}{l}\text { Supernova year } \\
\text { of flares }\end{array}$ & $\begin{array}{l}\text { Distance, } \\
\text { pc }\end{array}$ & $\begin{array}{c}\mathrm{N}_{\mathrm{F}}, \\
\text { atomm }{ }^{14} \mathrm{C}\end{array}$ & $\Delta^{14} \mathrm{C}=\frac{\mathrm{N}_{\mathrm{F}}}{\mathrm{N}_{\mathrm{o}}}, \%$ \\
\hline $\begin{array}{l}\text { Gemini nova } \\
\text { AD } 437\end{array}$ & 21,500 & $0.3 \cdot 10^{22}$ & $1.3 \cdot 10^{-5}$ \\
\hline $\begin{array}{c}\text { Auriga A } \\
\text { AD } 683\end{array}$ & 19,000 & $0.4 \cdot 10^{22}$ & $1.3 \cdot 10^{-5}$ \\
\hline $\begin{array}{c}\text { Cassiopeia nova } \\
\text { AD } 902 \\
\text { Taurus A }\end{array}$ & 1630 & $0.5 \cdot 10^{24}$ & $0.2 \cdot 10^{-2}$ \\
\hline $\begin{array}{l}\text { (Crab Nebula) } \\
\text { AD } 1054\end{array}$ & $1100-11,880$ & $\begin{array}{r}1.2 \cdot 10^{24}- \\
-1.2 \cdot 10^{22}\end{array}$ & $\begin{array}{r}0.4 \cdot 10^{-2} \\
-0.4 \cdot 10^{-4}\end{array}$ \\
\hline $\begin{array}{l}\text { Cassiopeia nova } \\
\text { AD } 1182\end{array}$ & 24,750 & $0.2 \cdot 10^{22}$ & $0.7 \cdot 10^{-5}$ \\
\hline $\begin{array}{l}\text { Scorpia nova } \\
\text { AD } 1203\end{array}$ & 24,750 & $0.2 \cdot 10^{22}$ & $0.7 \cdot 10^{-5}$ \\
\hline $\begin{array}{c}\text { Cassiopeia B } \\
\text { ('Tucho Brahe's) } \\
\text { AD } 1572\end{array}$ & $360-3260$ & $\begin{array}{r}1.1 \cdot 10^{25}- \\
-1.3 \cdot 10^{23}\end{array}$ & $\begin{array}{r}0.3 \cdot 10^{-1} \\
-0.4 \cdot 10^{-3}\end{array}$ \\
\hline $\begin{array}{l}\text { Ophiuchus nova } \\
\text { (Kepler's) } \\
\text { AD } 1604\end{array}$ & 10,900 & $1.2 \cdot 10^{22}$ & $0.4 \cdot 10^{-4}$ \\
\hline $\begin{array}{c}\text { Cassiopeia A } \\
\text { AD } 1700 \\
\text { Vela }\end{array}$ & 3400 & $2 \cdot 10^{23}$ & $0.4 \cdot 10^{-3}$ \\
\hline $10^{4}$ BP & 400 & $0.9 \cdot 10^{25}$ & $0.3 \cdot 10^{-1}$ \\
\hline
\end{tabular}




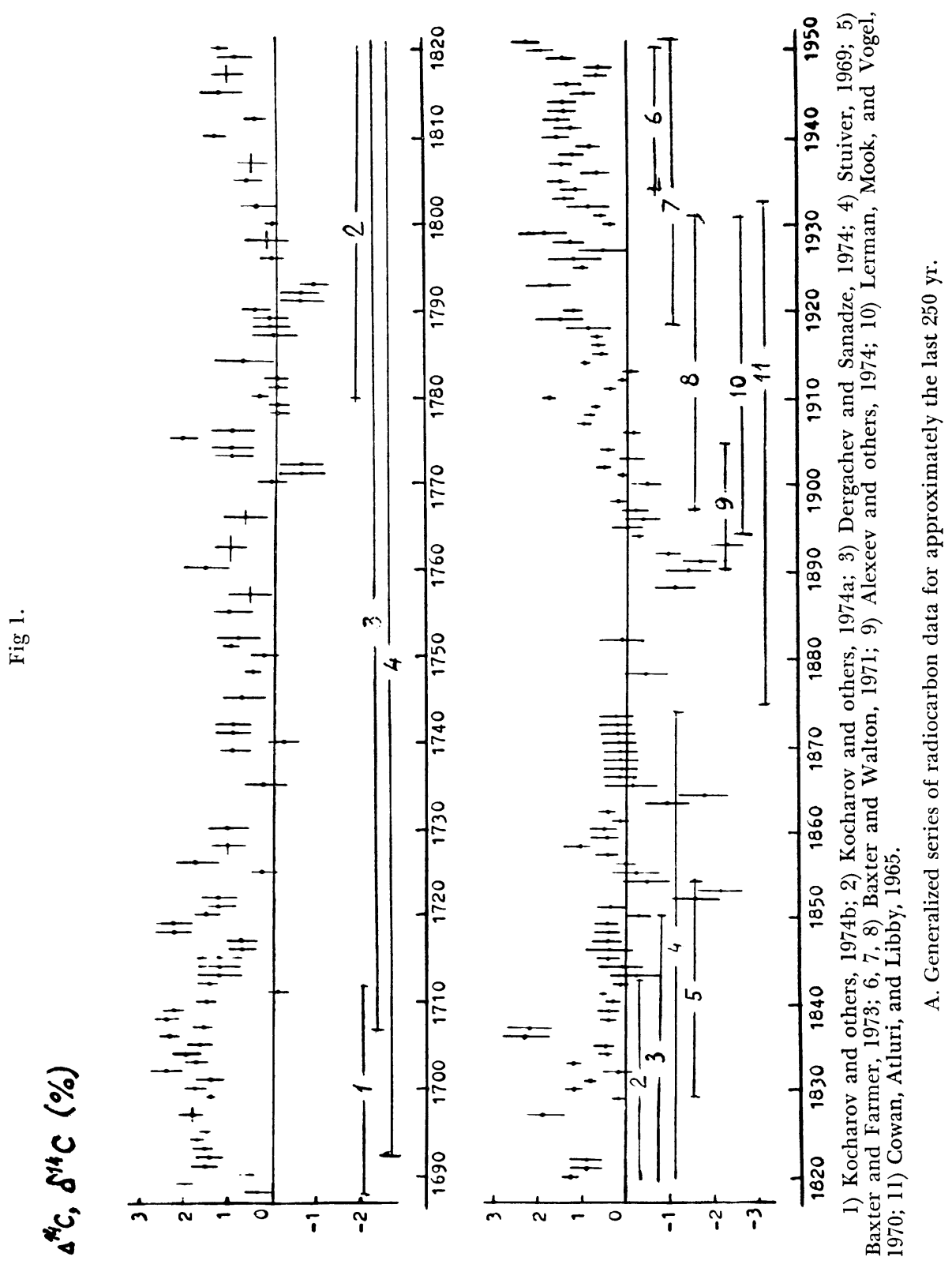


But supernovae and pulsars are all so distant from the earth that their cosmic rays will reach the solar system in tens of thousands of years. The age of pulsars and their distance from the earth may possibly be determined through an investigation requiring a longer time series of tree rings of known age.

Long-lived isotopes may be used for pulsars with ages exceeding the radiocarbon range. Povinec (1979) has shown that the maximum in the activity of ${ }^{10} \mathrm{Be}$ and ${ }^{26} \mathrm{Al}$ in basal sediments of ca $3.5 \cdot 10^{6}$ years ago might be explained by a corpuscular flux from the pulsar of PSR 0950-08.

\section{Solar activity and radiocarbon data}

In order to obtain detailed information on the variations of the ${ }^{14} \mathrm{C}$ content over very long time intervals, a short series of experimental data from various laboratories on the concentration of ${ }^{14} \mathrm{C}$ were combined into a unified generalized series (Dergachev, Tleugaliev, and Zhitorchuk, 1976). This interval includes the most reliable data on sunspot numbers and the most detailed results on ${ }^{14} \mathrm{C}$ content changes in samples. To obtain the unified generalized series, one of the longest series was taken and the others were compared with them. In this procedure, mean values of the individual series were compared. After this, autocorrelation functions and spectral density were calculated between the generalized series of radiocarbon data and the data on the sunspot numbers.

The power spectrum of these series of data on ${ }^{14} \mathrm{C}$ content shows a maximum at frequencies corresponding to periods of approximately 11 and 80 years (fig 1). Such cyclicities are also traced in solar activity. However, amplitudes of these harmonics differ for quantities being compared. Indeed, the 80-year harmonic for the generalized series of ${ }^{14} \mathrm{C}$ data has approximately 3 times the amplitude of the 11-year oscilla-

Fig. 1.

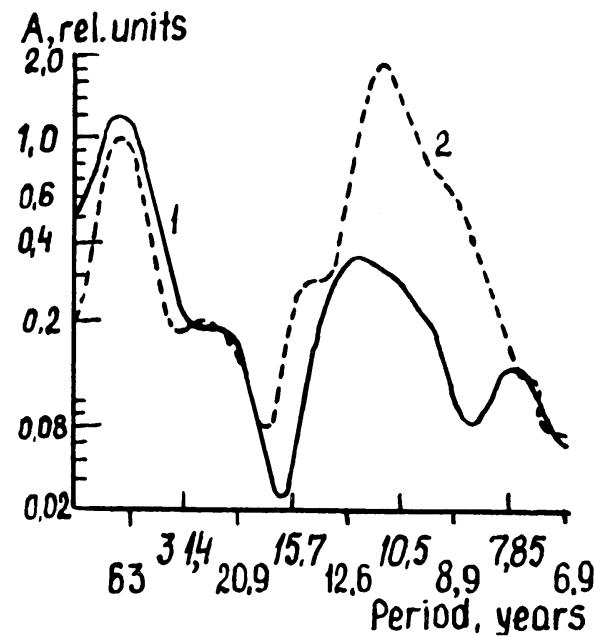

B. Spectra of a generalized series of data on ${ }^{14} \mathrm{C}$ content, 1, and sunspot numbers for the last $250 \mathrm{yr}, 2$. 
tion. Principal harmonics for the sunspot series have the 11-year cylicity. This pecularity can be explained by the smoothing action of the earth's atmosphere.

The phase difference spectrum calculated from these experimental data shows that phase shift of ${ }^{14} \mathrm{C}$ data relative to sunspot numbers for the 11-year harmonics is $5 \pm 2 \mathrm{yr}$, for the 80 -year cyclicities, it is $20 \pm 8$ $\mathrm{yr}$, which agrees with theoretical estimates.

A study of ${ }^{14} \mathrm{C}$ content variations over the time interval, 4500 to 7000 BP, in which the geomagnetic field reached a minimum, shows an 80-90-year cyclicity manifesting itself at a 95 percent confidence level. There are other cyclicities also.

An estimation of harmonic amplitude at different frequencies shows that the amplitude of the secular cycle in ${ }^{14} \mathrm{C}$ content variations during the period, 4500 to $7000 \mathrm{BP}$, was about 2.5 times larger than now. This may also account for the larger scatter of ${ }^{14} \mathrm{C}$ content measurements over this period. The major conclusion here is the existence of periodicities in ${ }^{14} \mathrm{C}$ content caused by solar activity, $i e$, the manifestation of cyclic activity is typical for the sun on such a long time scale.

\section{Radiocarbon concentration in the geomagnetic field extrema}

One of the important and complex problems of space physics is the problem of long-term variations of cosmic rays having characteristic times that exceed the time over which direct observations have been made. It is known that the geomagnetic field modifies the flux of cosmic rays which incident on the earth. Using archaeomagnetic measurements of the geomagnetic field intensity, the extreme values of this field were established. Studying the mutual spectra of the ${ }^{14} \mathrm{C}$ content series with the series of geomagnetic field intensity, the quantitative side of this problem can be investigated.

Let us consider a relationship between the extreme changes of geomagnetic field intensity and the corresponding changes of ${ }^{14} \mathrm{C}$ content (fig 2). The generalized series of geomagnetic (Bucha, 1970; Burlatskaya, 1970; Kitazawa and Kobayashi, 1968; Smith, 1967) and radiocarbon data, (Ralph, Michael, and Han, 1973), which were averaged by Dergachev and Tuichiev (1977) over 50 years, show a negative correlation between the series. The coefficient of linear correlation for these two series is $-0.77 \pm 0.2$. During periods of high or low magnetic moment, the amplitude of various phenomena that could affect the ${ }^{14} \mathrm{C}$ content of the earth's atmosphere must change. Any variation of the geomagnetic moment causes variations in the cosmic ray flux in the vicinity of the earth and, thus, the cutoff rigidities for primary particles must change. The amplitude of cosmic ray variations must be higher when the dipole moment is small, ie, vertical cutoff rigidities for the incident particles are small and vice versa. In this case, the global average rate of formation of ${ }^{14} \mathrm{C}$ becomes less or more sensitive to solar activity. During periods of a small dipole moment, the low-energy particles may penetrate to lower geomagnetic latitudes, and consequently, these particles may 
Fig 2.

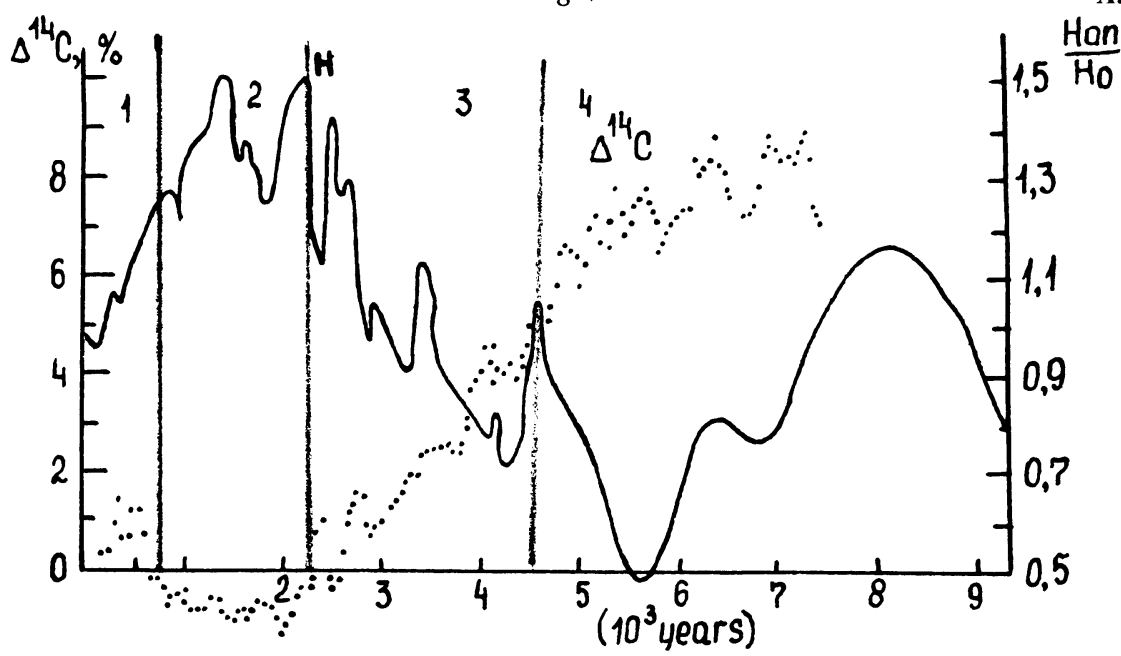

A. Generalized series of archaeomagnetic field intensity $\left(\mathrm{H}_{\mathrm{an}} / \mathbf{H}_{\mathbf{0}}\right)$ and $\Delta^{14} \mathrm{C}$ averaged over 50 years, for the last few thousand years. Four time intervals: 1) 0-750; 2) $750-2200$; 3) 2200-4500; 4) >4500 BP.
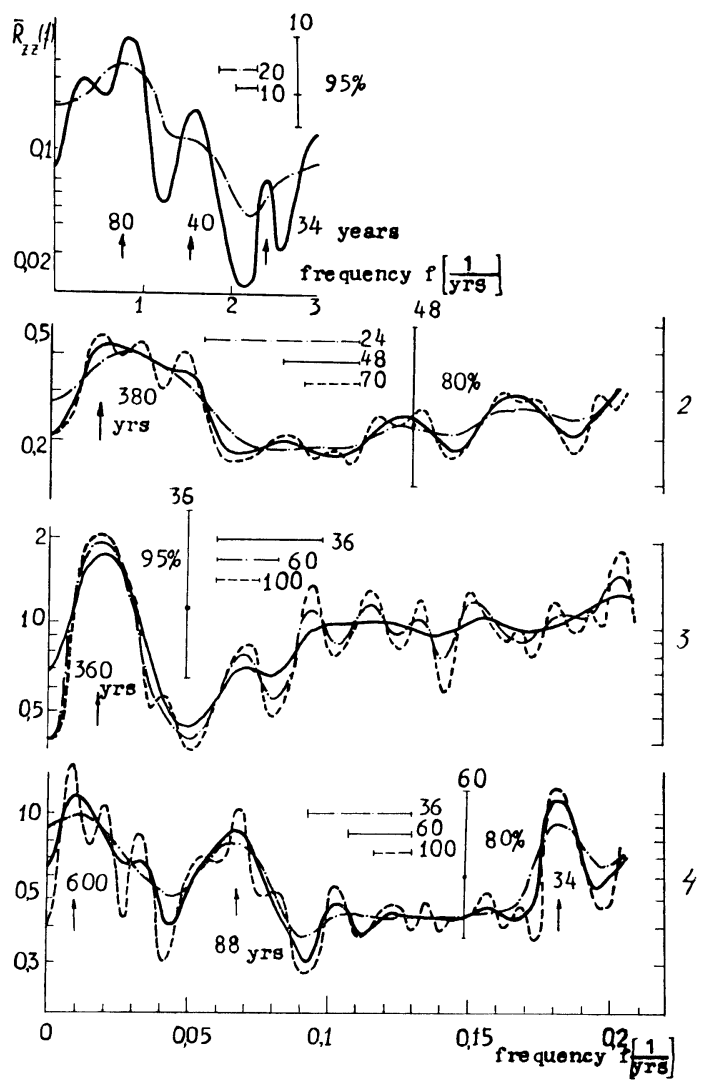

B. Smoothed sampling estimates of the normalized spectrum for the ${ }^{14} \mathrm{C}$ content for the Tukey window at various cutoff points (horizontal lines) for time intervals: 1) $0-500$; 2) $750-2200$; 3) $2200-4500$; 4) $4500-7000$ BP. Vertical lines are confidence inter- 
make an additional contribution to the formation of ${ }^{14} \mathrm{C}$ and the overall amplitude of the ${ }^{14} \mathrm{C}$ content variations must be higher (Dergachev, 1976). It should be noted that in periods when the geomagnetic field is maximal, the manifestation of the influence of short-period cycles of solar activity on the ${ }^{14} \mathrm{C}$ content must be reduced, and vice versa. Four time intervals in series data on the ${ }^{14} \mathrm{C}$ content 0 to 500 and 4500 to 7000 вP minimum of the geomagnetic field, and 750 to 2200 BP maximum of this field and 2200 to $4500 \mathrm{BP}$, were studied by Dergachev and Tuichiev (1977). The periods 0 to 500 years and 4500 to 7000 years are expected to reveal solar activity cyclicities of different duration. Also expected is a decrease in the amplitude of solar activity variation during the period of field intensity from 750 to $2200 \mathrm{BP}$.

In the first interval, periodicities of $\sim 80$ and $\sim 34$ years are manifested in the ${ }^{14} \mathrm{C}$ spectrum, which are significant at the 95 percent confidence level. In the second interval, calculations show the presence of one peak corresponding to $\sim 380$ years. In the third interval, there is one broad peak corresponding to $\sim 360$ years with a large amplitude. In the fourth interval, the periods of $\sim 600, \sim 80, \sim 34$ years are observed (the relative amplitude of the 600 -year cycle exceeds the amplitudes of the $\sim 80$ - and 34 -year cycles).

The spectral analysis that was performed for the ${ }^{14} \mathrm{C}$ series demonstrates that the 600,80 to 90 , and 34 to 40 -year periods are isolated when geomagnetic field intensity is minimal. These results suggest that the obtained periods are of solar origin.

The period, $\sim 360$ years, may be caused by variations in geomagnetic field intensity. The presence of a proper period in different archaeomagnetic data (Burlatskaya, 1970) and results of mutual spectral analysis of data on ${ }^{14} \mathrm{C}$ concentration and geomagnetic field intensity support this assumption.

Hence, a study of geomagnetic field influence on the ${ }^{14} \mathrm{C}$ level is very important for the investigation of solar activity.

\section{The stable isotopes in tree rings}

Natural organisms, including tree rings, contain carbon, oxygen, and hydrogen which are trapped from the environment in exchange processes. Relative abundance of stable isotopes in plant materials depends on the isotopic composition of an environment and on the degree of isotopic fractionation during photosynthesis and on other exchange processes. Since climatic changes may affect transfer rates and distribution of ${ }^{14} \mathrm{C}$ between reservoirs, it is important to find climatic information in tree rings. Unfortunately, the change in exchange reservoirs of carbon due to climatic changes has not yet been sufficiently studied. Climatic changes affecting the ${ }^{14} \mathrm{C}$ level of the earth's atmosphere is also not well known.

Variations in hydrogen, carbon, and oxygen isotope ratios in the annual rings of wood may be used as a paleoclimatic indicator. The study of these isotopes provides useful data on the temperature of air, water and soil in the growth location of a plant. 
An integrated study of the content of both radiocarbon and stable isotopes of hydrogen, carbon, and oxygen in well-dated tree rings is important not only to establish the quantitative relationship between variations of ${ }^{14} \mathrm{C}$ content and climatic changes, but also to reconstruct climatic patterns in the past over a long period. These studies are also necessary to establish the regularity of exchange process variations in the interior of the dynamic carbon reservoir. As a result, the division of "climatic" from "cosmic" components in recorded ${ }^{14} \mathrm{C}$ variations may be attempted for the last tens of thousand years. Analysis of the concentration of radioactive and stable isotopes in organic matter and climatic factors shows the perspective of these investigations (Akhmetkereev, Dergachev, and Kocharov, 1978).

Some theoretical and experimental data on ${ }^{14} \mathrm{C}$ content will be considered in Dergachev (1980).

Thus, only integrated investigations of both radioactive and stable isotopes in annual rings of wood can clarify many questions connected with the intensity of cosmic-ray changes, climatic changers, and the problem of man and environment.

\section{REFERENCES}

Akhmetkereev, S Kh, Dergachev, V A, and Kocharov, G E, 1978, Variations in the stable isotopes concentration in dated organic samples in Dergachev, V A and Kocharov, G E , eds, Leningrad seminar on cosmophysics, 9th, Proc: Leningrad, p 71-110 (in Russian).

Alexeev, V A, Lavrukhina, A K, Milnikova, Z K, Smirnov, I V, and Sulerzhitsky, L D, 1974, Solar cosmic rays and variations of radiocarbon in the earth's atmosphere, in Kocharov, G E and Dergachev, V A, eds, All-Union conf astrophysical phenomena and radiocarbon, 4th, Proc: Tbilisi Univ Press, p 39-46 (in Russian).

Baxter, B S and Farmer, J C, 1973, Radiocarbon: short-term variations: Earth Planetary Sci Letters, v 20, p 295-299.

Baxter, B S and Walton, A, 1971, Fluctuations of atmospheric carbon-14 concentrations during the past century: Royal soc [London] Proc, v A 321, p 105-127.

Bucha, V, 1970, Influence of the earth's magnetic field on radiocarbon dating, in Olsson, I U, ed, Radiocarbon variations and absolute chronology, Nobel symposium, 12th, Proc: New York, John Wiley and Sons, p 501-510.

Burlatskaya, S P, 1970, The change of geomagnetic field intensity for the past 8500 years using the world archaeomagnetic data: Geomagnetism and aeronomie, v 10, no. 4 (in Russian).

Cowan, C, Atluri, C R, and Libby, W F, 1965, Possible anti-matter content of the Tunguska meteor of 1908: Nature, v 206, p 861-865.

Dergachev, V A, 1976, The intensity of cosmic rays in the past, in European symposium on cosmic rays, 5th, rept: Leeds, England.

1980, Experimental and theoretical data on radiocarbon variation in the earth's atmosphere in the past, in Stuiver, Minze and Kra, Renee, eds, Internatl radiocarbon conf, 10th, Proc: Radiocarbon, v 22, no. 2, p 328-336.

Dergachev, V A and Kocharov, G E, 1977, Corpuscular and $\gamma$-radiation of supernova and radiocarbon content in the earth's atmosphere: Internatl cosmic ray conf, 15th: Plovdiv, v 12, p 209-215.

Dergachev, V A, Kocharov, G E, and Rumyantsev, S A, 1970, Supernovae stars and radiocarbon, in Kocharov, G E, Dergachev, V A, and Mirianashvili, G M, eds, All-Union conf on astrophysical phenomena and radiocarbon, Proc: Tbilisi Univ Press, p 11-20 (in Russian).

Dergachev, V A, Kocharov, G E, and Tleugaliev, S Kh, 1977, Cosmic ray intensity annual variations for the last several centuries, in Internatl cosmic ray conf, 15th, Plovdiv, v 2, p 197-202.

Dergachev, V A and Sanadze, A A, 1974, The ${ }^{14} \mathrm{C}$ concentration in dendrochronologically dated samples, in Kocharov, $\mathrm{G}$ E and Dergachev, V A, eds, All-Union conf on astrophysical phenomena and radiocarbon, 4th, Proc: Tbilisi Univ Press, p 63-72 (in Russian). 
Dergachev, V A, Tleugaliev, S Kh, and Zhitorchuk, Yu V, 1976, The ascertainment of the cyclic oscillation of radiocarbon content in the generalized line of data for the period 1688-1951: Physico-Technical Inst Preprint, N 511 (in Russian).

Dergachev, V A and Tuichiev, N, 1977, Mutual spectral analysis of data on ${ }^{14} \mathrm{C}$ concentration and geomagnetic field intensity: Acad sci USSR Bull, Physics ser, v 41, p 163-169.

Kitazawa, K and Kobayashi, K, 1968, Intensity variation of the geomagnetic field during the past 4000 years in South America: Jour geomag geol, v 20, p 7-19.

Kocharov, G E, Arslanov, Kh A, Dergachev, V A, Rumyantzev, A A, Chernov, S B, and Goncharov, V F, 1974a, Solar activity and the concentration of ${ }^{14} \mathrm{C}$ in the tree rings for 1780-1838 measured by means of single-channel scintillation device stabilized by light pulse, in Dergachev, V A and Kocharov, G E, eds, All-Union conf on astrophysical phenomena and radiocarbon, 4th, Proc: Tbilisi Univ Press, p 19-37 (in Russian).

Kocharov, G E, Dergachev, V A, Sementzov, A A, Romanova, E N, Rumyantzev, A A and Malanova, N S, 1974b, Concentration of radiocarbon in tree-rings 1564-1583, 1593-1615, 1688-1712, in Dergachev, V A, and Kocharov, G E, eds, All-Union conf on astrophysical phenomena and radiocarbon 4th, Proc: Tbilisi Univ Press, p 47-62 (in Russian).

Konstantinov, B P and Kocharov, G E, 1965, Astrophysical phenomena and radiocarbon: Dokl Akad Nauk SSSR, v 165, p 63-64 (in Russian).

Lerman, L C, Mook, W G, and Vogel, J C, $1970,{ }^{14} \mathrm{C}$ in tree rings from different localities, in Olsson I U, ed, Radiocarbon variations and absolute chronology, Nobel symposium, 12th, Proc: New York, John Wiley and Sons, p 275-301.

Libby, W F, 1946, Atmospheric helium three and radiocarbon from cosmic radiation: Physics Rev, v 69, p 671-672.

Lingenfelter, R E and Ramaty, R, 1970, Astrophysical and geophysical variations in ${ }^{14} \mathrm{C}$ production, in Olsson, I U, ed, Radiocarbon variations and absolute chronology, Nobel symposium, 12th, Proc: New York, John Wiley and Sons, p 513-537.

Povinec, P, 1979, Utilization of cosmogenic isotopes for study of cosmic ray intensity variations caused by supernova explosion: Acad Sci USSR Bull, Physics ser, v 43, no. 4.

Ralph, E K and Michael, H N, 1970, MASCA radiocarbon dates for sequoia and bristlecone-pine samples, in Olsson, I U, ed, Radiocarbon variations and absolute chronology, Nobel symposium, 12th, Proc: New York, John Wiley and Sons, p 619-624.

Ralph, E K, Michael, H N, and Han, M C, 1973, Radiocarbon dates and reality, MASCA newsletter, $\mathrm{v}$ 9, p 1-20.

Smith, P J, 1967, The intensity of the ancient geomagnetic field: A review and analysis: Royal Astron Soc Geophys Jour, v 12, p 321-362.

Stuiver, Minze, 1969, Yale natural radiocarbon measurements IX: Radiocarbon, v 11, p 545-568.

Suess, H E, 1970, Bristlecone pine calibration of the radiocarbon time scale 5200 вс to the present, in Olsson, I U, ed, Radiocarbon variations and absolute chronology, Nobel symposium, 12th, Proc: New York, John Wiley and Sons, p 303-311.

DISCUSSION

Suess: Where did the ${ }^{14} \mathrm{C}$ data come from?

Dergachev: We used Suess' and Ralph and others' measurements of ${ }^{14} \mathrm{C}$ content in the atmosphere to obtain the generalized radiocarbon data on long time scale.

Barbetti: What data did you use for the curve you showed for geomagnetic strength?

Dergachev: We average the geomagnetic data derived in the various archaeomagnetic laboratories and obtained generalized series of geomagnetic field intensity. Most of the geomagnetic data from the different USSR regions was compiled by S P Burlatskaya from the Institute of Earth’s Physics, Moscow. 